\title{
CFD study of ventilation for indoor multi-zone transformer substation
}

\author{
Mohamad Kanaan, Khaled Chahine* \\ Faculty of Engineering, Beirut Arab University, Debbieh, Lebanon
}

Corresponding Author Email: k.shahine@bau.edu.lb

https://doi.org/10.18280/ijht.360112

Received: 15 October 2017

Accepted: 1 February 2018

\section{Keywords:}

ventilation schemes, numerical modeling, transformer substation, turbulent flow, thermal field

\begin{abstract}
Ventilating electrical rooms with intense heat emission sources is imperative to prevent workers' injury and damage to equipment. This paper investigates by means of computational fluid dynamics (CFD) the performance of seven proposed ventilation schemes for a multi-zone transformer room of an indoor substation in Beirut city. To this end, an indoor multi-zone substation with four transformers was simulated using ANSYS/Fluent 15.0 with different proposed ventilation schemes. The location of inlet louvers was fix, while the positions of four exhaust outlets were changed throughout the CFD simulations to determine the best-case scenario providing the lowest levels of temperatures in the operating zone and in the vicinity of transformers. The analysis showed that the cooling effect improves as the elevation of the exhaust fans decreases. The obtained results can be used to make some recommendations for design and optimization of similar ventilation projects of indoor transformer rooms.
\end{abstract}

\section{INTRODUCTION}

An MV/LV transformer substation transforms the medium voltage supplied by the distribution network (e.g. $20 \mathrm{kV}$ ), into voltage values suitable for the power supply of the low voltage lines (e.g. $400 \mathrm{~V}$ ). A substation is usually made of prefabricated concrete, steel or glass-fiber reinforced polyester and contains the transformer, the $\mathrm{MV}$ and $\mathrm{LV}$ switchgear, the interconnections and auxiliary equipment and circuits. A prefabricated substation is usually preferred owing to its ease of transportation, rapid on-site installation, and compliance with standards.

The service temperatures of transformer substations are specified in the service conditions of the IEC 62271-202 standard [1]. The maximum temperature is $40^{\circ} \mathrm{C}$ over 24 hours, except for extreme climates, where the range is from $50^{\circ} \mathrm{C} / 40^{\circ} \mathrm{C}$ for cold climates and $-5^{\circ} \mathrm{C} /+50^{\circ} \mathrm{C}$ for very hot climates. Other ventilation and air conditioning design specifications for indoor substations require that the temperature in areas for human activities should not exceed $40^{\circ} \mathrm{C}$ and indoor temperature should not exceed $45^{\circ} \mathrm{C}$ [2]. These climatic conditions along with the waste heat given off as a byproduct of transformer operation cause temperature rise in the substation. Since the temperature inside the transformer tank directly depends on the surrounding air temperature, excessive temperature increase inside the substation can reduce the operating life of the transformer by adversely affecting its insulation properties. Given the fact that the transformer is the most expensive component in a substation, it becomes of utmost importance that this heat be dissipated. This is done by the radiation exchanges with the surrounding walls of the substation and more importantly by the air circulating by natural convection through the ventilation grills of the substation and. However, at high outdoor temperatures the buoyancy-driven free convection is not sufficient to remove the waste heat, and mechanical ventilation is often used.

Assessing the thermal behavior of a certain substation design is essential before the substation is fabricated and put into service, especially when strict design limitations exist. This is because obtaining a top-oil temperature that exceeds the permissible limits set by International Standards $[1,3]$ after actually implementing the design invalidates the design. In this case, another design would be required. To avoid such a time consuming and wasteful approach, methods based on mathematical models of substation ventilation designs can be used to study the thermal behavior in the designing phase prior to implementation. They are generally characterized by their versatility to test designs tailored to specific conditions and try scenarios involving the variation of load conditions or external factors such as environment temperature. The literature classifies these methods into thermal circuit methods and finite element methods.

A simple ventilation model for transformer substations was proposed in [4]. The model is based on two equations: one equation for the heat transferred to the ventilation air and a second equation for the heat dissipated through the walls of the substation. The model takes as input the main parameters associated with the ventilation performance of a substation such the power loss in the transformer and the dimensions of the substation and outputs the estimates of the outflow air and the transformer mean temperature rise over the ambient temperature. A limitation of this model is that it does not give the enclosure class of the substation, as required by IEC standard [1].

The transient equivalent thermal circuit model developed in [5] represents an alternative approach to the thermal modeling of transformer substations. This model requires measurements of the local temperature values in the substation and configuration of the ventilation grills considered. In [6], the same approach was improved by accounting for the temporal variation of the thermal 
resistances and capacitances of the top-oil, of the ventilation air and of the different components of the substation enclosure. A limitation of the transient equivalent thermal circuit model is that it cannot be used to optimize the thermal performance in the designing phase since it is based on discrete temperature measurements of an existing system.

A more comprehensive approach to ventilation that can handle design and optimization objectives is the numerical approach. Numerical methods were used to validate the performance of a ventilation system installed in a mine [7], predict ventilation in underground hydropower stations [8], validate a design for uniform airflow distribution in duct ventilation [9], and predict fire characteristics under various ventilation conditions in an aircraft cargo compartment [10]. Numerical methods have been also used to study the thermal behavior of a transformer substation. In [11], the finite element method was used to solve the energy and the NavierStokes equations in a flow domain corresponding to the air inside a transformer substation. This approach permitted to analyze the effect of the aperture of the ventilation grills, the transformer load and the ambient temperature in the air temperature distribution inside the substation. In [12], a differential model of the air circulation and heat transfer was developed for a half-buried transformer substation and solved by means of the finite volume method. This model is more realistic than the model in [11], as it assumes a turbulent flow. The model allows the enclosure class of the substation to be determined and for the analysis of the air velocity and temperature distributions.

The aim of this paper is to investigate by CFD modeling the performance of the air distribution system of a multi-zone transformer room of an indoor substation located in Beirut. Seven ventilation schemes with different exhaust outlet arrangements are proposed while the position of air inlets is fixed. The best ventilation scheme is determined based on the analysis and comparison of the predicted airflow and thermal fields.

\section{PHYSICAL MODEL}

The transformer room is $16.15 \mathrm{~m}$ long, $10.90 \mathrm{~m}$ wide, and $11.30 \mathrm{~m}$ high and is divided into four zones each containing a transformer of heat output $55 \mathrm{~kW}$ (Figure 1). The wall partitions are of height $3.5 \mathrm{~m}$ and thickness $0.15 \mathrm{~m}$. For safety purposes, four fire dampers that close in case of fire are fitted in the partitions between Zone 1 and Zone 3, and between Zone 2 and Zone 4.

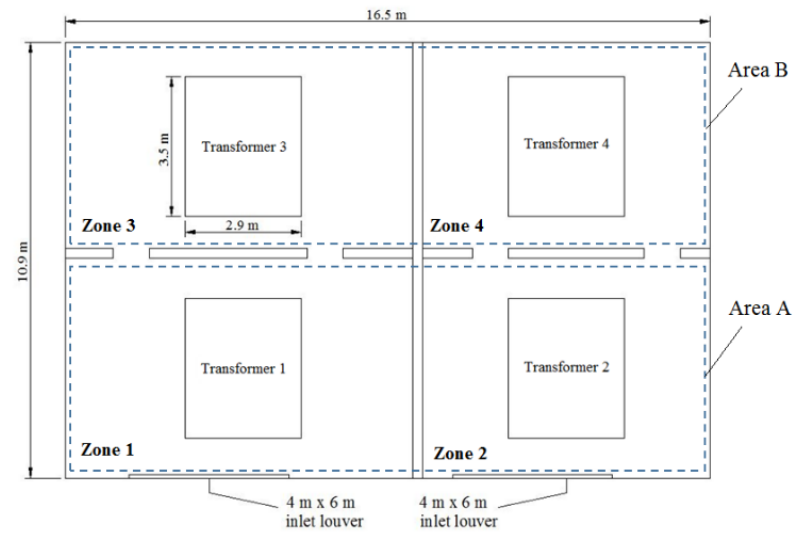

Figure 1. Plan view of the transformer room
Two $6 \mathrm{~m}(\mathrm{~W}) \times 4 \mathrm{~m}(\mathrm{H})$ air intake louvers are installed in one of the room walls. The slats of the louvers are tilted downwards at an angle of $25^{\circ}$ to prevent rainwater from entering the electrical room. From the energy balance, the ventilation rate is estimated to be $27.4 \mathrm{~kg} / \mathrm{s}$ for a design outdoor temperature of $37^{\circ} \mathrm{C}$ and assuming adiabatic walls to disregard heat losses to the outdoor air through walls. This conservative approach is used to minimize any possible underestimation of indoor thermal fields in the numerical simulations and thus have more confidence in the design recommendations drawn from the CFD results. Four identical exhaust fans are used for ventilating the room and the air outlets are $2 \mathrm{~m} \times 1.5 \mathrm{~m}$. Seven air outlet arrangement schemes are proposed with the same position of air inlets. The ventilation schemes are shown in Figure 2, where the four air outlets are mounted in the ceiling for Scheme a and wall mounted at elevations $8 \mathrm{~m}$ for Schemes b, c, d, and e, 5 $\mathrm{m}$ for Scheme $\mathrm{f}$, and $3.6 \mathrm{~m}$ for Scheme $\mathrm{g}$.

\section{CFD MODEL}

CFD has proven to be a powerful tool for the prediction of fluid and heat flows in indoor environments and has numerous successful applications in the literature [12-15].

A detailed steady-state three-dimensional CFD model is developed using ANSYS Fluent 15.0 [16] to predict the airflow patterns and thermal fields inside the transformer room.

For simplification purposes and in order to reduce the mesh size, the transformers are represented by cuboids of dimensions $3.5 \mathrm{~m}(\mathrm{~L}) \times 2.9(\mathrm{~W}) \times 3 \mathrm{~m}(\mathrm{H})$. A tetrahedral mesh is used for the computational geometry with inflation at the walls. The quality of the mesh is ensured with a maximum skewness less than 0.9. For grid independence test, the number of cells is varied from 275,820 to $2,112,752$ for the case of Scheme a. It is found that the values of predicted air temperatures at the exhausts cease to change drastically (variation less than 5\%) after the cell count of 902,076. Therefore, the mesh size to be used for all simulation cases will be in the same order to obtain accurate results at minimum computational cost.

The standard k-epsilon model with standard wall function is used to simulate turbulence. Buoyancy is modeled using the ideal gas law. The surface-to-surface (S2S) model is used to account for radiation [15]. This model calculates the energy exchange in an enclosure of gray-diffuse surfaces. The energy reflected from a surface is computed using the absolute temperature, emissivity, and reflectivity of that surface and the energy flux incident on it from the surroundings. The radiation exchange between two surfaces depends on their size, separation distance, and orientation. These parameters are taken into account using view factors computed by the CFD solver.

The STANDARD discretization is used for the pressure term, whereas the second-order discretization is used for the governing equations. The velocity and pressure terms are coupled using the SIMPLE scheme. The solution is considered convergent when the volume-average air temperature in the lower zone is stabilized, the scaled residuals reach $5 \times 10^{-5}$, and the net heat and mass balances are less than $1 \%$ of the minimum flux in the computational domain. 


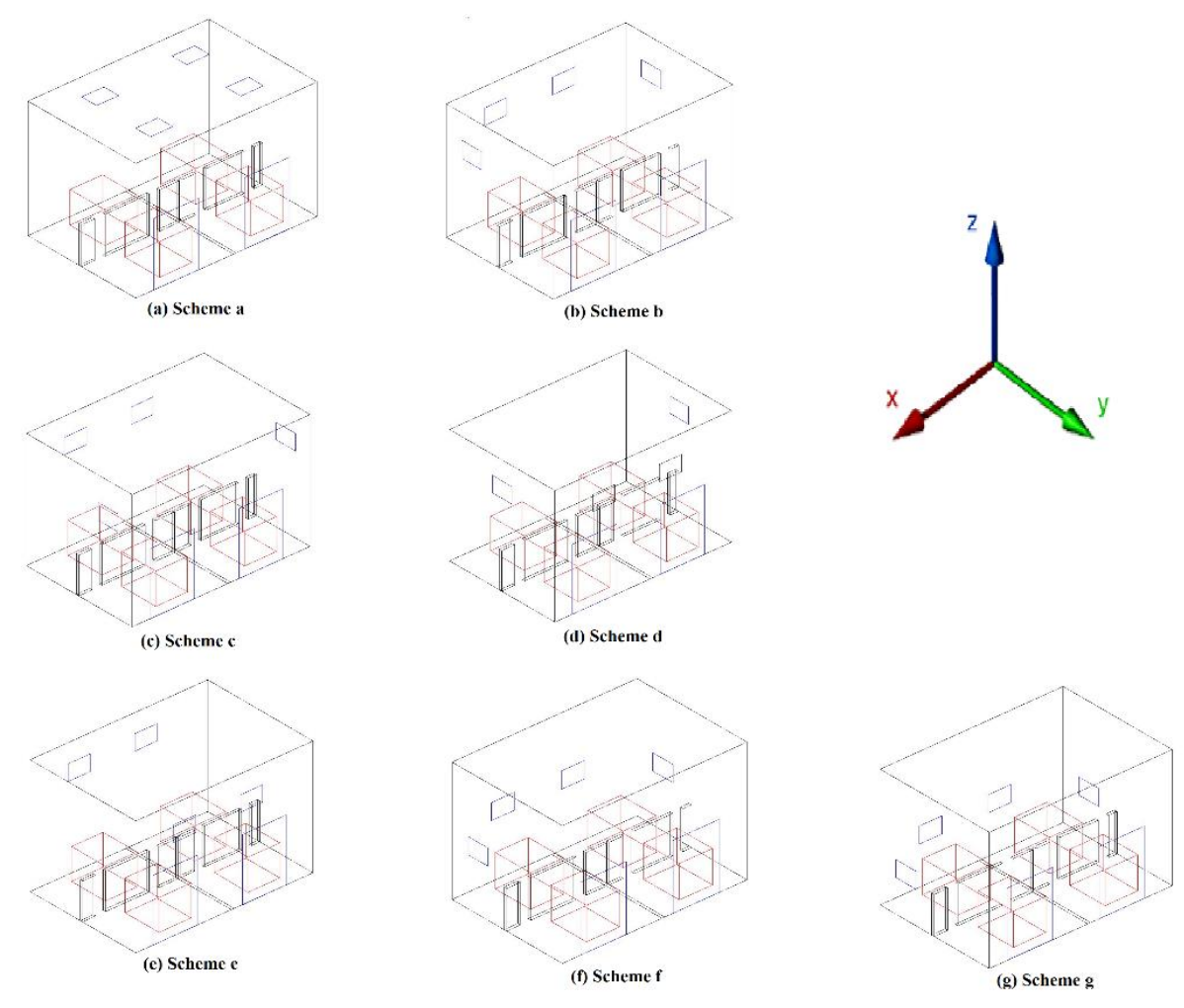

Figure 2. Schematics of the proposed ventilation schemes

\section{MATHEMATICAL MODEL}

The solver of ANSYS Fluent uses the finite volume method to solve the conservation equations of mass, momentum, and energy. This method converts the partial differential equation into separate algebraic equations over elements or cells called finite volumes. The values of the flow properties such as velocity, pressure, and temperature are computed at the node of each cell of the computational grid.

\subsection{Continuity equation}

The flow field in the simulated space is governed by the basic incompressible continuity equation:

$$
\nabla \mathbf{U}=0
$$

Where $\nabla$ is the gradient operator and $\mathbf{U}$ is the velocity vector.

\subsection{Momentum equation}

For each cell of the computational grid, the flow field is governed by the following steady-state differential momentum equation (Navier-Stokes equation) for incompressible flow:

$$
\rho \mathbf{g}-\nabla \mathbf{p}+\mu \Delta \mathbf{U}=0
$$

where $\mathbf{p}$ is the pressure, is the dynamic viscosity, and is the Laplace operator.

\subsection{Energy equation}

For any infinitesimal control volume in the flow field, the differential energy equation for incompressible flow is expressed at steady state as follows:

$\nabla(\alpha \nabla T)+q=0$

where $\mathrm{T}$ is the temperature, is the thermal diffusion coefficient, and $q$ is the heat generated per unit volume.

\section{BOUNDARY CONDITIONS}

\subsection{Walls}

No-slip condition is applied to all walls. This condition assumes that the air has zero velocity relative to the solid boundaries. A heat flux of $1,132.85 \mathrm{~W} / \mathrm{m}^{2}$ is attributed to transformers' walls while zero-heat flux is defined at other walls to ignore any heat loss to the outside through them.

\subsection{Inlets and outlets}

Pressure inlet boundary condition is imposed to the inlet louvers with temperature of $37^{\circ} \mathrm{C}$ and inflow direction making an angle of $25^{\circ}$ with the horizontal. The outlets are defined using exhaust fan boundary condition each with target mass flow rate $6.85 \mathrm{~kg} / \mathrm{s}$.

The boundary conditions are detailed in Table 1 . 
Table 1. Boundary conditions used in the simulations

\begin{tabular}{|c|c|}
\hline Boundary & Details \\
\hline Inlet & $\begin{array}{c}\text { Pressure inlet, Direction vector }\left(0, \cos 25^{\circ}, \sin \right. \\
\left.25^{\circ}\right), \text { Total temperature: } 37^{\circ} \mathrm{C}\end{array}$ \\
\hline Outlets & $\begin{array}{c}\text { Exhaust fan, Target mass flow rate: } 6.85 \mathrm{~kg} / \mathrm{s}, \\
\text { Backflow turbulent intensity: } 5 \%, \text { Backflow } \\
\text { hydraulic diameter: } 1.714 \mathrm{~m}\end{array}$ \\
\hline $\begin{array}{c}\text { Station's } \\
\text { walls }\end{array}$ & Material: $25 \mathrm{~mm}$ concrete, $\varepsilon=0.9$ \\
& $\rho=2,200 \mathrm{~kg} / \mathrm{m}^{3}, \mathrm{c}_{\mathrm{p}}=840 \mathrm{~J} / \mathrm{kgK}, \lambda=1.7 \mathrm{~W} / \mathrm{mK}$ \\
\hline Transformers & $\begin{array}{c}\text { No-slip, Heat flux: } 1,132.85 \mathrm{~W} / \mathrm{m}^{2} \\
\text { Material: cast iron, } \varepsilon=0.8\end{array}$ \\
& $\rho=7,197 \mathrm{~kg} / \mathrm{m}^{3}, \mathrm{c}_{\mathrm{p}}=500 \mathrm{~J} / \mathrm{kgK}, \lambda=667$ \\
$\mathrm{~W} / \mathrm{mK}$
\end{tabular}

\section{RESULTS AND DISCUSSIONS}

The CFD predictions of the indoor airflow and thermal fields are used to evaluate the performance of the ventilation system in use. In general, the convective heat transfer enhanced by mixing and back and forth motion of the air results in effective heat removal and cooling effects and, as a result, favors one ventilation scheme over another.

The proposed ventilation schemes are assessed and compared based on the predicted volume-averaged air temperatures in the operating zone and in the vicinity of each transformer presented in Table 2. The operating zone extends from the floor to the height of $3.5 \mathrm{~m}$ and the vicinity of a transformer is defined as the region surrounding the transformer at a distance of $0.5 \mathrm{~m}$ (rectangular microclimate). Table 3 shows the predicted average surface temperatures of the transformers for each ventilation scheme.

The air velocity distributions on horizontal sampling plane $(\mathrm{z}=1.5 \mathrm{~m})$ are shown in Figure 3. The thermal fields at $\mathrm{z}=$ $1.5 \mathrm{~m}$ and at a cut plane $(\mathrm{x}=4.45 \mathrm{~m})$ are presented in Figures 4 and 5 , respectively.

Three-dimensional air streamlines for each case are also presented in Figure 6 to analyze and better understand the advantages and disadvantages of each proposed ventilation scheme. Results show that Scheme g exhibits the best performance yielding a volume-averaged air temperature of $39.0^{\circ} \mathrm{C}$ in the operating zone and $41.1-41.6^{\circ} \mathrm{C}$ in the proximities of transformers.

Table 2. Predicted volume-averaged air temperatures in ${ }^{\circ} \mathrm{C}$ for all proposed schemes

\begin{tabular}{|l|c|c|c|c|c|c|c|}
\hline & Scheme a & Scheme b & Scheme c & Scheme d & Scheme e & Scheme f & Scheme g \\
\hline Microclimate 1 & 42.5 & 43.0 & 41.8 & 43.3 & 42.2 & 41.1 & 41.1 \\
\hline Microclimate 2 & 44.0 & 43.3 & 41.2 & 43.4 & 41.2 & 40.9 & 40.5 \\
\hline Microclimate 3 & 63.9 & 45.1 & 43.2 & 45.8 & 44.0 & 42.5 & 41.4 \\
\hline Microclimate 4 & 61.3 & 47.0 & 44.7 & 48.2 & 45.0 & 43.2 & 41.6 \\
\hline Operating zone & 43.4 & 39.4 & 39.7 & 40.1 & 40.2 & 39.3 & 39.0 \\
\hline
\end{tabular}

Table 3. Predicted average surface temperatures of transformers in ${ }^{\circ} \mathrm{C}$ for all proposed schemes

\begin{tabular}{|c|c|c|c|c|c|c|c|}
\hline & Scheme a & Scheme b & Scheme c & Scheme d & Scheme e & Scheme f & Scheme g \\
\hline Transformer 1 & 139.3 & 132.7 & 98.0 & 137.4 & 100.7 & 133.8 & 100.3 \\
\hline Transformer 2 & 148.5 & 149.0 & 95.1 & 143.2 & 95.9 & 133.6 & 100.1 \\
\hline Transformer 3 & 360.7 & 184.1 & 112.2 & 191.7 & 114.0 & 170.8 & 108.1 \\
\hline Transformer 4 & 327.3 & 187.2 & 113.0 & 211.1 & 114.2 & 176.0 & 109.0 \\
\hline
\end{tabular}

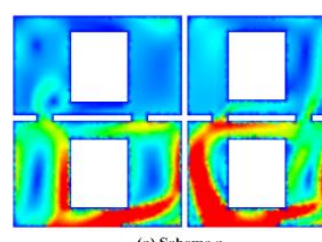

(a) Schemea

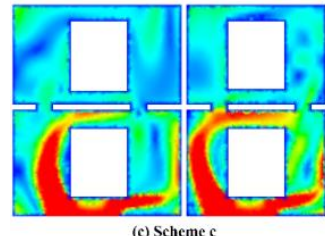

(c) Scheme c

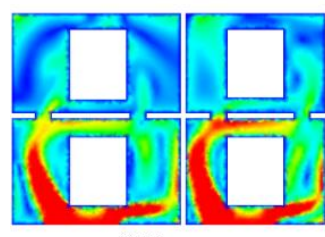

(e) Scheme e

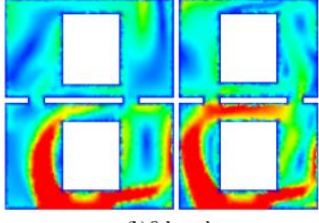

(b) Scheme b

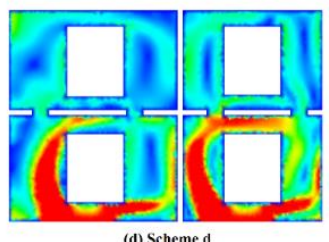

(d) Scheme d

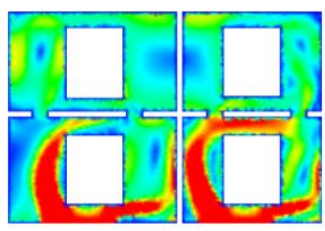

(i) Scheme f
Velocity

$\mathrm{z}=1.5 \mathrm{~m}$
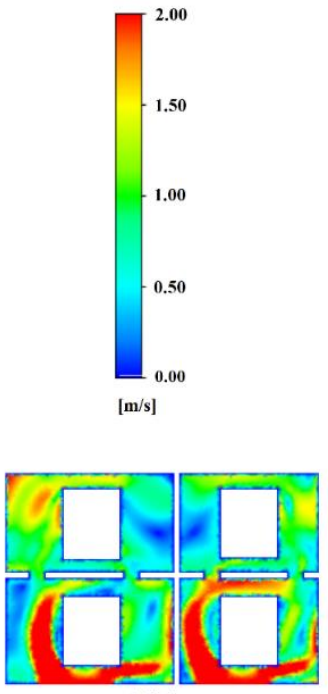

(g) Scheme g

Figure 3. Velocity contour plots at $\mathrm{z}=1.5 \mathrm{~m}$ for all proposed schemes 

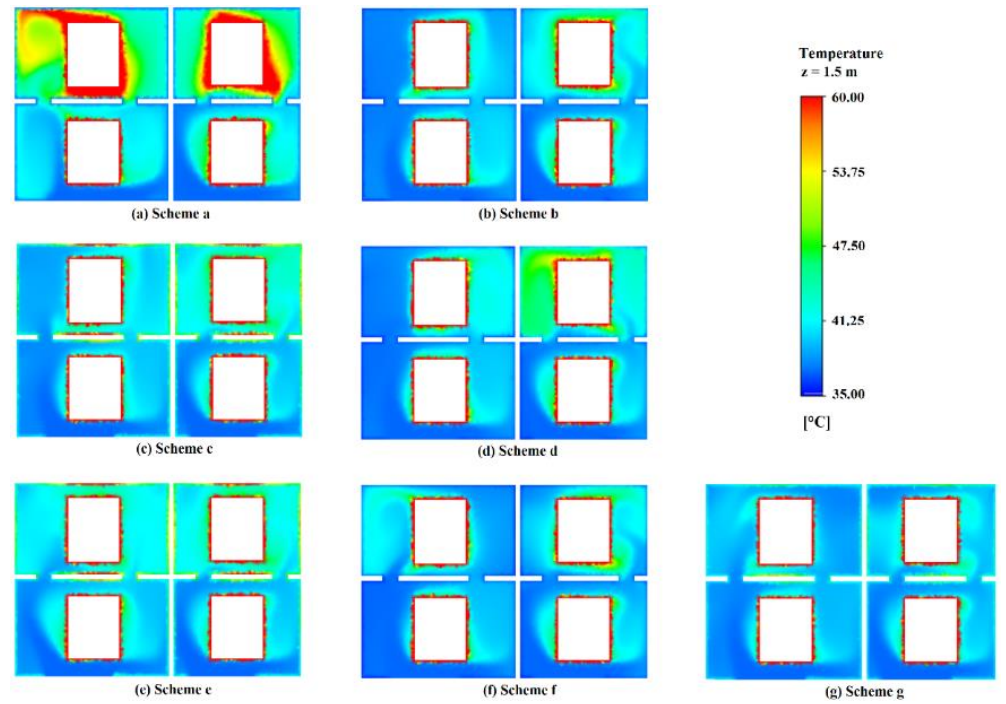

Figure 4. Temperature contour plots at $\mathrm{z}=1.5 \mathrm{~m}$ for all proposed schemes
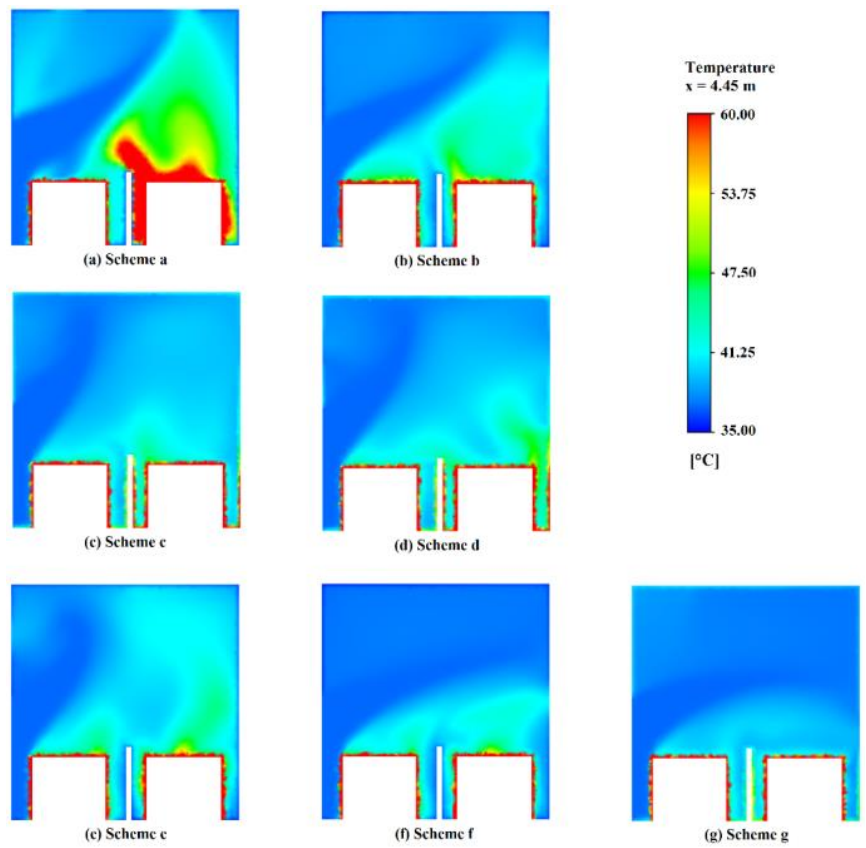

Figure 5. Temperature contour plots at $\mathrm{x}=4.45 \mathrm{~m}$ for all proposed schemes
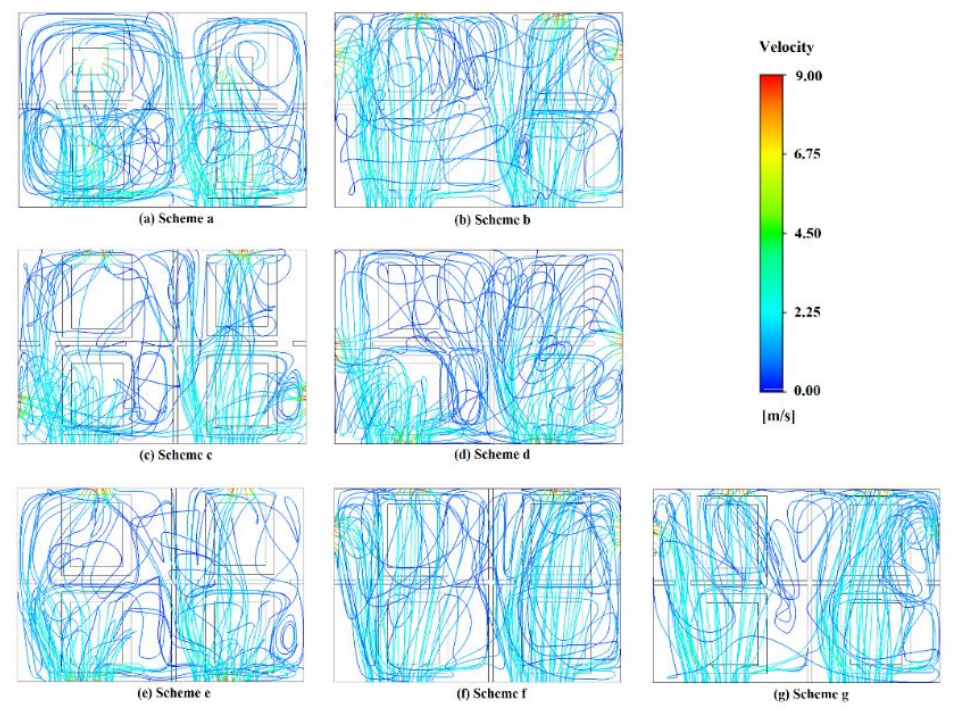

Figure 6. Top view of 3D streamline charts for all proposed schemes 


\subsection{Scheme a}

The ventilation air jets strike the transformers in Area A, which cools down their surfaces and destroys the thermal plumes that they develop (Figures 5.a, 6.a). The surrounding air is carried by the ventilation air toward the ceiling where it is vented out. The significant cooling effects induced by the substantial air movement in Area A make the air temperature in the vicinity of Transformers 1 and 2 within the acceptable range. In Area $\mathrm{B}$, however, there is no direct contact of ventilation air with the transformers because of the partitions blocking the flow (Figure 3.a). Here, rising plumes are established above the transformers and they mix with the room air at high elevations in the proximity of exhaust outlets. This airflow pattern results in poor cooling performance in Area B as shown in Figure 4.a since heat from transformers displaces mainly by radiation and unforced convection.

\subsection{Scheme b}

As indicated in Figure 6.b and Figure 3.b, the ventilation jets carry the surrounding air toward Area B passing by the transformers in Area A and cooling them down. All exhaust outlets are in Area B and at a level lower than the ceiling level which results in better heat removal than in Scheme a. The bulk of the airflow that reaches Area B is immediately vented out conveying the warm air that rises buoyantly from the vicinity of the transformers in that area (Figure 5.b). This explains the significant drop in predicted air temperatures within Area B when compared with those of Scheme a (Figure 4.b).

\subsection{Scheme c}

The advantage of this scheme over Scheme $b$ is that not all exhaust outlets are positioned in Area B. In fact, the existence of two outlets in Area A allows the forth and back motion of the air providing better cooling effect. This explains the lower predictions of average air temperature in the operating area for Scheme $\mathrm{c}$ as shown in Figure 4.c and Figure 5.c.

\subsection{Scheme d}

As shown in Figure 6.d, a part of the airflow is immediately exhausted from the space through the sidewall outlets without removing much heat and the remainder is carried to Area B. In this area, two vortices are developed between the sidewalls of the transformers and the wall partition forming two dead zones (Figure 3.d) that lead to higher predicted values of air temperature in the operating area when compared with Schemes $\mathrm{b}$ and $\mathrm{c}$ as shown in Figure 4.d and Figure 5.d.

\subsection{Scheme e}

As indicated in Figure 4.e and Figure 5.e, Scheme e exhibits good cooling effects with acceptable predictions of air temperature in operating area. Figure 6.e shows that the ventilation air reaches Area B and is either vented out through the outlets on the opposite side of the inlet louvers or circles backwards and flows to the outlets mounted above the louvers. This remarkable mixing pattern of the airflow facilitates ventilation and hence ensures satisfactory ranges of air temperature in the operating area.

\subsection{Schemes $f$ and $g$}

Results reveal that Scheme c has the best cooling effect compared with Schemes a, b, c, d, and e. The same configuration of exhaust outlets used in Scheme $\mathrm{c}$ is proposed in Schemes $\mathrm{f}$ and g, except that the elevation of the outlets is varied. While the elevation was $8 \mathrm{~m}$ in Scheme c, it is changed to be $5 \mathrm{~m}$ for Scheme $\mathrm{f}$ and $3.5 \mathrm{~m}$ for Scheme $\mathrm{g}$. As shown in Figure 3.f and Figure 3.g, air velocity is greater in the operating zone when the exhaust outlets are located at lower elevations, which enhances the convective heat transfer at the sides of transformers and then results in lower air temperature levels in the operating zone. Moreover, when an outlet is located just above the transformer, the latter's thermal plume is vented out before expanding and mixing with the indoor air (Figure 6.g). Scheme g is then the bestproposed scenario providing the best cooling effects in the operating zone as shown in Figure 4.g and Figure 5.g.

\section{CONCLUSIONS}

An indoor multi-zone substation with four transformers was simulated using ANSYS/Fluent 15.0 with different proposed ventilation schemes. The location of inlet louvers is fix, while the positions of four exhaust outlets were changed throughout the CFD simulations in order to determine the best-case scenario providing the lowest levels of air temperatures in the operating zone and in the vicinity of transformers. The following conclusions were drawn from the performed analysis:

1. Scheme a with four ceiling-mounted exhaust fans was the worst case as predicted air temperatures reached the highest levels exceeding $60^{\circ} \mathrm{C}$ in the vicinity of transformers in Area B.

2. It is recommended to locate two exhaust fans on the wall facing the inlet louvers and the other two fans on the adjacent walls within Area A. This configuration provides safe and acceptable ranges of air temperature in the operating zone and also in the neighborhood of all transformers. The analysis showed that the cooling effect improves as the elevation of the exhaust fans decreases.

\section{REFERENCES}

[1] IEC 62271-202. (2006). High-voltage switchgear and controlgear, part 202: high voltage/low voltage prefabricated substations. IEC Standard.

[2] Hua Z, Min R, Neng G, Bu Y. (1993). 35-110 kV Substation Design (GB50059-92). China Planning Press, China.

[3] IEC 60076-2. (1997). Power transformers, part 2: temperature rise. IEC Standard, $2^{\text {nd }} \mathrm{ed}$.

[4] Menheere WMM. (1995). Transformer stations and natural ventilation. CIRED $13^{\text {th }}$ International Conference on Electricity Distribution, Brussels, Belgium, pp. 1-23.

[5] Radakovic Z, Maksimovic S. (2002). Non-stationary thermal model of indoor transformer stations. Electrical 
Engineering Archiv fur Elektrotechnik 84(2): 109-117. http://dx.doi.org/ 10.1007/s00202-001-0111-5

[6] Iskender I, Mamizadeh A. (2011). An improved nonlinear thermal model for MV/LV prefabricated oilimmersed power transformer substations. Electrical Engineering Archiv fur Elektrotechnik 93(1): 9-22. http://dx.doi.org/ 10.1007/s00202-010-0186-y

[7] Hurtado JP, Acuna EI. (2015). CFD analysis of 58 Adit main fans parallel installation for the 2015-2019 underground developments of the new level mine project. Applied Thermal Engineering 90:1109-1118. http://dx.doi.org/ 10.1016/j.applthermaleng.2015.05.014

[8] Liu Y, Wang S, Deng Y, Ma W, Ma Y. (2016). Numerical simulation and experimental study on ventilation system for powerhouses of deep underground hydropower stations. Applied Thermal Engineering 105: 151-158. http://dx.doi.org/ 10.1016/j.applthermaleng.2016.05.101

[9] Ye WB. (2017). Design method and modeling verification for the uniform air flow distribution in the duct ventilation. Applied Thermal Engineering 110: 573-583. 10.1016/j.applthermaleng.2016.08.177

http://dx.doi.org/

[10] Lu KH, Mao SH, Wang J, Lu S. (2017). Numerical simulation of the ventilation effect on fire characteristics and detections in an aircraft cargo compartment. Applied Thermal Engineering 124: 14411446. http://dx.doi.org/ 10.1016/j.applthermaleng.2017.06.128

[11] Loucaides N, Ioannides Y, Efthymiou V, Georghiou GE. (2010). Thermal modeling of power substations using the finite element method. 7th Mediterranean Conference and Exhibition on Power Generation, Transmission, Distribution and Energy Conversion (MedPower 2010), Agia Napa, Cyprus, pp. 1-5.
[12] Ramos JC, Rivas A, Morcillo JM. (2005). Numerical thermal modelling of the natural ventilation of a halfburied transformer substation using CFD techniques. Progress in Computational Heat and Mass Transfer 2: 929-934.

[13] Vega MG, Díaz KMA, Oro JMF, Tajadura RB, Morros CS. (2008). Numerical 3D simulation of a longitudinal ventilation system: memorial tunnel case. Tunnelling and Underground Space Technology 23(5): 539-551. http://dx.doi.org/ 10.1016/j.tust.2007.10.001

[14] Kanaan M, Ghaddar N, Ghali K. (2016). Localized airconditioning with upper-room UVGI to reduce airborne bacteria cross-infection. Building Simulation 9(1): 6374. http://dx.doi.org/ 10.1007/s12273-015-0250-7

[15] Voelker C, Diewald M. (2015). CFD simulation and measurement of the heat transfer from building material specimens to the indoor environment. 14th Conference of International Building Performance Simulation Association, Hyderabad, India, pp. 891-896.

[16] ANSYS Inc. ANSYS15.0.7 - Engineering Simulation and 3-D Design Software.

\section{NOMENCLATURE}

p pressure

T temperature

U Velocity vector

\section{Greek symbols}

$\alpha$

$\Delta$

$\nabla$

$\mu$ thermal diffusion coefficient

Laplace operator

gradient operator

dynamic viscosity 